\title{
Tidal and gravity waves study from the airglow measurements at Kolhapur (India)
}

\author{
R N Ghodpage ${ }^{1, *}$, Devendraa Silngh ${ }^{2}$, R P Singh ${ }^{3}$, \\ G K MukherJeE ${ }^{1}$, P VOHAT ${ }^{4}$ and A K Singh ${ }^{5}$ \\ ${ }^{1}$ Medium Frequency Radar, Indian Institute of Geomagnetism, Shivaji University Campus, \\ Kolhapur 416004 , India. \\ ${ }^{2}$ Indian Institute of Tropical Meteorology, Pune 411 008, India. \\ ${ }^{3}$ Department of Physics, Banaras Hindu University, Varanasi 221 005, India. \\ ${ }^{4}$ Geophysical Services, Makarpura Road, ONGC, Vadodara 390 009, India. \\ ${ }^{5}$ Department of Physics, University of Lucknow, Lucknow 226 007, India. \\ ${ }^{*}$ Corresponding author.e-mail: rupesh_ghodpage@rediffmail.com
}

Simultaneous photometric measurements of the OI $557.7 \mathrm{~nm}$ and $\mathrm{OH}(7,2)$ band from a low latitude station, Kolhapur $\left(16.8^{\circ} \mathrm{N}, 74.2^{\circ} \mathrm{E}\right)$ during the period $2004-2007$ are analyzed to study the dominant waves present in the $80-100 \mathrm{~km}$ altitude region of the atmosphere. The nocturnal intensity variations of different airglow emissions are observed using scanning temperature controlled filter photometers. Waves having period lying between 2 and 12 hours have been recorded. Some of these waves having subharmonic tidal oscillation periods $4,6,8$ and 12 hours propagate upward with velocity lying in the range $1.6-11.3 \mathrm{~m} / \mathrm{s}$ and the vertical wave length lying between 28.6 and $163 \mathrm{kms}$. The other waves may be the upward propagating gravity waves or waves resulting from the interaction of inter-mode tidal oscillations, interaction of tidal waves with planetary waves and gravity waves. Some times, the second harmonic wave has higher vertical velocity than the corresponding fundamental wave. Application of these waves in studying the thermal structure of the region is discussed.

\section{Introduction}

Atmospheric tides, planetary waves and gravity waves play significant role in dynamic features of the Mesosphere and Lower Thermosphere (MLT) region by transporting energy and momentum horizontally and vertically upward and also providing dynamical linkage between the lower atmosphere and the MLT region. Atmospheric tides are the global response of the atmosphere to the periodic forcing of solar heating; propagate westward following the motion of the Sun (Chapman and Lindzen 1970) with periodicities equal to the solar day and its sub-harmonics (i.e., 24, 12, 8, $6,4,3,2 \mathrm{hr}$, etc). Tides are classified as migrating and non-migrating. The non-migrating tides lead to strong longitudinal variations in amplitude and phase of diurnal tide, whereas the migrating tides contain diurnal, semidiurnal, terdiurnal and other harmonics. The diurnal ( $24 \mathrm{hr}$ period) tide is mainly excited by the direct absorption of the sunlight by water vapour in the troposphere and the stratosphere, whereas the semidiurnal tide (12 hr periods) is caused by ozone heating in the upper stratosphere and the lower mesosphere. Studies of the diurnal and the semidiurnal tides and its

Keywords. Tidal and gravity wave; airglow emission; mesosphere and lower thermosphere (MLT); planetary waves. 
influences in the mesospheric region at various geographical locations have been made using lidar (Taylor et al. 1999; Liu et al. 2007), radar (Zhang et al. 2003; Forbes et al. 2004; Manson et al. 2004), airglow emissions (Wiens and Weill 1973; Takahashi et al. 1998; Lopez-Gonzalez et al. 2005; Won et al. 2007) and space-based airglow observations (Abreu and Yee 1989; Shepherd et al. 1995, 1998, 2004).

Airglow emissions are an outcome of chemiluminescence property of ambient atomic molecular species in the middle and the upper atmosphere. The variability of emission intensity is dominated by a long period as well as a short period structure that are commonly attributed to the passage of tides, gravity waves, planetary waves and their interplay. A large variation in diurnal behaviour of the airglow emission rates as a function of the year and of the latitude has been observed (Manson et al. 2004). Lopez-Gonzalez et al. (2005) analyzed airglow observations (the $\mathrm{O}_{2}$ atmospheric band and the OH Meinel band) during the period 1998-2003 and showed that the amplitudes of the diurnal variation from summer to late autumn decrease by more than a factor of two compared with those in the winter and spring. Both temperatures and emission rates showed the dominance of waves with predominantly semidiurnal modulation throughout the year. However, during spring, the semidiurnal variation changes to a diurnal type. They also observed upward energy propagation during most of the year, with some indication of downward energy propagation close to the equinoxes. Taori and Taylor (2010) analyzing mesospheric $\mathrm{O}_{2}$ airglow emission intensity and temperature data showed the dominant presence of terdiurnal $(8 \mathrm{hr}$ periods) tide-like wave and quasi 5 days wave leading to a possible signature and interplay of tides and planetary waves. Ground observations (Vincent et al. 1998) as well as satellite observations (Burrage et al. 1995; McLandress et al. 1996) showed the existence of a strong semiannual tidal amplitude variation in the mesosphere.

The wavy structures observed in the mesosphere night glow intensity variations have also been attributed to the upward propagating gravity waves generated in the lower atmospheric regions (Krassovsky 1972; Hines and Tarasick 1987; Tarasick and Hines 1990; Tarasick and Shepherd 1992a, 1992b; Fagundes et al. 1995; Nakamura et al. 1999) principally by deep convective activity of thunderstorm (Brown et al. 2004; Hecht et al. 2004; Snively and Pasko 2008; Vadas et al. 2009; Siingh et al. 2011, 2012) and orography effects (Tsuda et al. 1989; Eckermann and Preusse 1999). Recently Das et al. (2011) have proposed heating effect during dust storm also to be one of the probable generation mechanisms of gravity wave in the middle atmosphere. Multispectral night glow emissions recorded at low latitude stations showed the presence of gravity waves with periods of few hours (Molina et al. 1985; Takahashi et al. 1985). Short period (tens of minutes) and short horizontal wavelength (tens of kms) gravity waves in the night glow emissions have also been observed (Nakamura et al. 1999; Hecht et al. 2001; Hecht et al. 2004; Pautet et al. 2005). Hecht et al. (2009) showed the presence of long period $(\sim 2 \mathrm{hr})$ and large horizontal wavelength $(\sim 300-400 \mathrm{~km})$ gravity waves as well as short period (15-25 min) and small horizontal wavelength $(\sim 30-45 \mathrm{~km})$ gravity waves in the airglow data over Alice Spring, Australia. The short period waves might have been trapped/ducted by thermal ducts and took several hours to reach the mesopause region. The temperature profile recorded by SABER (Sounding of Atmosphere using Broadband Emission Radiometry) showed the presence of thermal duct (Fadnavis et al. 2009). Winds critically control the formation of the duct and hence variations in the wind direction and amplitude may account for sporadic/shortlived observations of the short and the long period waves.

Recently, Narayanan et al. (2010) reported the presence of large- and small-scale wave features perpendicularly aligned to each other in the airglow observations, which were associated with gravity wave dynamics. The large scale wave with a horizontal wavelength of $\sim 43 \mathrm{~km}$ propagated towards the north-west at an apparent phase speed of $\sim 48 \mathrm{~m} / \mathrm{s}$. These waves near $88 \mathrm{~km}$ altitude experienced reflection when the background wind was blowing in an opposite direction to that of wave propagation. The small scale waves with periodicities between 23 and $50 \mathrm{~min}$ were continuously appearing and disappearing in different parts of the sky within the field of view of the imaging camera. The small scale waves could have been generated locally by the convective instability $(\mathrm{Li}$ et al. 2005a, 2005b). The smaller period (less than $12 \mathrm{hr}$ ) waves showed a strong wave dissipation throughout the year except during equinox transitions when a large (a factor of about 3-4) amplitude growth was deduced from the analysis of $\mathrm{O}_{2}(0-1)$ and $\mathrm{OH}(6-2)$ atmospheric band emissions (Taori et al. 2007).

In the middle atmosphere, the thermal structure has been attributed to turbulent heating associated with gravity waves (Fadnavis et al. 2009) and tidal waves (Dao et al. 1995). The thermal structures so formed depend on wave parameters (Fritts and Alexander 2003). As the wave parameters change from day-to-day and with latitude, we make an attempt to study the characteristic feature of waves present in the airglow emission intensity observed at Kolhapur, a low latitude 
station. The data for the years 2004, 2005 and 2007 are used to decipher any possible variation in wave parameters with year. In the present paper, simultaneously measured nightglow emissions data of OI $557.7 \mathrm{~nm}$ and $\mathrm{OH}$ band are analyzed to study wavy structures in the mesosphere and the lower thermosphere region. The analysis showed presence of terdiurnal and sub-harmonics of tidal oscillations. Waves of shorter periods are also observed. Using the observation of emissions from the two different layers, we determine the horizontal wavelength and velocity of vertical wave propagation. Section 2 deals with observations and analysis of the data. Results and discussions are given in sections 3. Section 4 discusses tidal influences in airglow emissions and brief summary and conclusions are given in section 5 .

\section{Observations and analysis techniques}

Regular observations of the night airglow emissions, OI $557.7 \mathrm{~nm}$ and $\mathrm{OH}$ Meinel (683 and $692 \mathrm{~nm}$ ) bands have been carried out at the low latitude station Kolhapur $\left(16.8^{\circ} \mathrm{N}, 74.2^{\circ} \mathrm{E}\right)$ on clear and moonless nights since 1989 using filter scanning photometer having five optical filters with integration time of $30 \mathrm{~s}$ each. The half field of view of the photometer is $7.25^{\circ}$. Three Stepper Motors control the movement of five filters in the meridional and the azimuthal directions. Before starting observations, the azimuthal position and the position of particular filters were brought to a home position. The scanning photometer was kept in the north-south direction. Three optical sensors were used for this purpose to get the home position of the filters as well as the meridional and the azimuthal positions. The fillers have a band width of $1 \mathrm{~nm}$ and their temperature is controlled by a temperature controller at $25^{\circ} \mathrm{C}$. The temperature coefficient of filter is $0.011 \mathrm{~nm} /{ }^{\circ} \mathrm{C}$. At $25^{\circ} \mathrm{C}$, the transmission efficiency of filters is $\sim 60-70 \%$. The filter scanning photometer consists of a photomultiplier tube (EMI 9658B) as a detector which has a wide spectral response. Data from each filter are stored in the digital form in the hard disk of a PC through RS-232 port after amplification of the signal from the photomultiplier tube (EMI 9658B). The photometer was upgraded with a microprocessor for control and data acquisition and it takes about 2.5 minutes to complete one sequence of observations. The integration time of optical filters is $\sim 30 \mathrm{~s}$.

In the absence of a standard calibration source, we have used relative intensities in arbitrary unit. In order to study the wave features present in the MLT region, we consider only those clear sky days having more than 4 hours of continuous and simultaneous observations of the OI $557.7 \mathrm{~nm}$, and $\mathrm{OH}$ Meinel band emissions. The analysis is carried out for the period 2004-2007. For further analysis, airglow intensity values are averaged at an interval of 15 minutes. In this approach one can decipher wavy structures with periods more than 30 minutes (frequency $\sim 1 / 2 \mathrm{dT}$ ). To retrieve long period waves short period fluctuations are smoothed out. Long period waves mostly represent tidal structures and gravity waves originating from the troposphere and stratosphere.

The presence of the short period and the long period oscillations in the nocturnal airglow emissions have been studied using various mathematical filtering techniques (Daubechies 1988; Mukherjee 2003; Taori and Taylor 2010). In the present work, we developed and modified mat lab program for cosine wave fitting and used it for all dataset. From the raw data mean intensity value is determined, which is subtracted from the individual intensity data and mean intensity deviations are obtained. These intensity deviations are used for the cosine wave fitting and further analysis. The periodicity of waves and residuals are determined. Analyzing residuals, the dominant harmonic wave periodicity and amplitudes are estimated. The phase lags/leads are used to evaluate wave phase velocity.

\section{Results and discussion}

The nocturnal variations observed on 54 clear nights in OI $557.7 \mathrm{~nm}$ and $\mathrm{OH}(7,2)$ bands are analyzed using the technique discussed above. The total data length on individual nights is $\sim 9$ 10 hours. Based on the previous studies, it is assumed that the emission $557.7 \mathrm{~nm}$ comes from the $97 \mathrm{~km}$ altitude and the $\mathrm{OH}$ band is emitted at about $86 \mathrm{~km}$ altitude. To measure the wave parameters obtained in the data, a simple best fit wave perturbation cosine model is used (Taori et al. 2003, 2005) and periodicity, phase and amplitude of the primary wave and its sub-harmonics are estimated from the intensity of $\mathrm{OI}$ and $\mathrm{OH}$ emissions independently. The modelled best fit solutions were used to get the amplitude and phase information of the waves present in the intensity data. From all the plots it is evident that the data is dominated by long period wave with short period oscillations superposed on it.

Figure 1 shows the mean intensity deviations of the emission lines $(683,692 \mathrm{~nm})$ of $\mathrm{OH}$ band on the nights of March 12-13, 2007 and April 1112, 2007 respectively. The wave signature $(\sim 6 \mathrm{hr}$ period) seen in the mean intensity deviations could be due to the solar atmospheric tides. It is noted that the minimum mean intensity deviation value is observed around mid-night at about 23-24 hr 


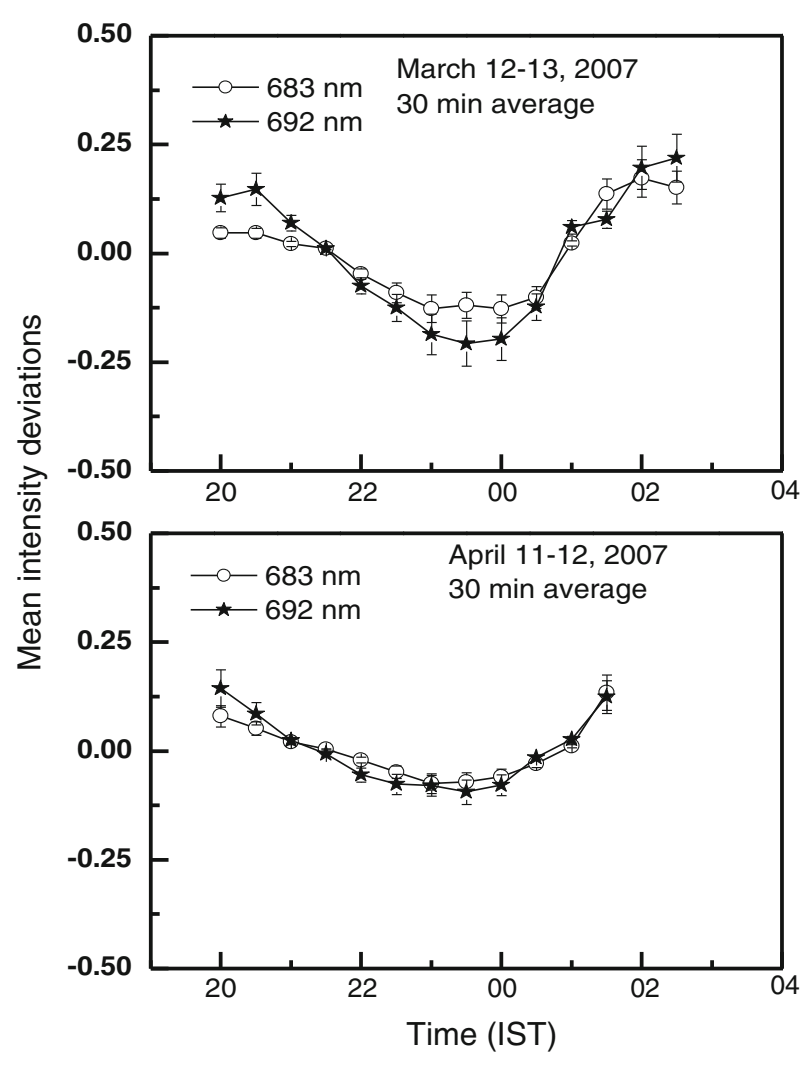

Figure 1. The mean intensity deviations of the $\mathrm{OH}$ emission lines $(683,692 \mathrm{~nm})$ with time in Indian Standard Time (IST) observed at Kolhapur for the night of March 12-13, 2007 (upper panel) and for the night of April 11-12, 2007 (lower panel).

and, the maximum mean intensity deviation occurs at the evening and early morning hours. The error bars show the range of airglow intensity under each deviation peak. Same nature is also observed on April 11-12, 2007. When we average the intensity data for four days and plot its variation with time, an interesting result emerges. Figure 2(a, b) shows four days (12-15 March 2007) average intensity variation with time for $\mathrm{OI} 557.7 \mathrm{~nm}$ and $\mathrm{OH}$ $(7,2)$ lines respectively, where (a) plots the mean intensity deviations of OI $557.7 \mathrm{~nm}$ (normalized to their mean intensity values) and (b) plots the mean intensity deviation of $\mathrm{OH}$ (normalized to their mean intensity value). A best fit to $\mathrm{OH}$ data is obtained. The periodicity from OI emission is $\sim 8.4 \mathrm{hr}$ and that from $\mathrm{OH}$ line it comes out to be $8 \mathrm{hr}$. The residual (obtained by subtracting from this long period oscillations) intensity deviations for $\mathrm{OI}$ and $\mathrm{OH}$ are shown in figure 2(c) and (d) respectively. The wave periods comes out to be 4.6 and $4.2 \mathrm{hr}$. Similarly figure $3(\mathrm{a}, \mathrm{b})$ shows the average variation of intensity deviations for $\mathrm{OI}$ and $\mathrm{OH}$ emissions on 10-13 April, 2007 and obtained period is $8.4 \mathrm{hr}$ for both the lines. However, the residual mean intensity deviations shown in figure $3(\mathrm{c}, \mathrm{d})$ yield wave period 2.2 and $4 \mathrm{hr}$ respectively for OI and $\mathrm{OH}$ emissions.
The nocturnal mean intensity deviations of OI $557.7 \mathrm{~nm}$ and $\mathrm{OH}(7,2)$ emissions for the night of February 14-15, 2004 are shown in the upper panel, along with the contributions from the first and the second harmonics (9 and $4.5 \mathrm{hr}$ periods) in the lower panels of figure 4 . Here it should be noted that although we had data for $9 \mathrm{hr}$ only, the cosine fitting for the data yielded $9 \mathrm{hr}$ of periodicity. The harmonic analyses provide the information of percentage contributions of different harmonics in the total wave structure. In the present case, the maximum percentage contribution comes from the second harmonics in both $\mathrm{OI}$ and $\mathrm{OH}$ emissions rather than the other harmonics. Because of this we chose the second harmonics for the comparison of $\mathrm{OH}$ and OI $557.7 \mathrm{~nm}$ emissions. The plots of two emissions are shown in the same figure to get the location of amplitude minima of wavy structure coming from the two different layers and it is inferred that the longer period wave $(\sim 9 \mathrm{hr})$ propagates upward. The mean intensity averaging process for 13-16 February, 2004, yield $8 \mathrm{hr}$ period for the OI emission and $9.6 \mathrm{hr}$ for the $\mathrm{OH}$ emissions. The wave period for the shorter wave comes out to be 2.4 and $4.4 \mathrm{hr}$ for the $\mathrm{OI}$ and $\mathrm{OH}$ emissions respectively (table 1 ). Table 1 summarises the results of analysis based on an average mean intensity deviations of three to four nights depending upon the availability of data.

The mean intensity deviations of OI $557.7 \mathrm{~nm}$ and $\mathrm{OH}$ emissions for the night of February 15-16, 2004 , along with the variation of amplitude of different harmonics $(9,4.5 \mathrm{hr})$ are shown in figure 5 . The phase propagation for the first harmonic seems to be downwards, whereas the second harmonic shows an upward propagation. The data for February 17-18, 2004, was analyzed (figure 6) and phase propagation for both the first and the second harmonics was found to be upward. The analysis of average mean intensity deviations for the period 13-16 February and 17-20 February 2004 show downward phase propagation both for the first and the second harmonics. In normal condition, downward wave propagation is not tenable. Such propagation in localized region may be observed due to the strong wind effect or the influence of multiwave mode coupling. Analysing OI and $\mathrm{OH}$ emission data, Fagundes et al. (1995) showed downward phase propagation with velocity in the range 4$10 \mathrm{~ms}^{-1}$ and vertical wavelength lying between 12 and $77 \mathrm{~km}$. Meriwether et al. (1998) using Rayleigh lidar observations showed a downward phase propagation of $1 \mathrm{~km} / \mathrm{hr}$ and explained it through a localized mechanism involving the coupling of gravity waves to the mesopause tidal structure. They suggested that in a critical layer in which phase speed of the propagating gravity wave matches the combined speeds of background mean wind and 
March 12-15, 2007; Kolhapur
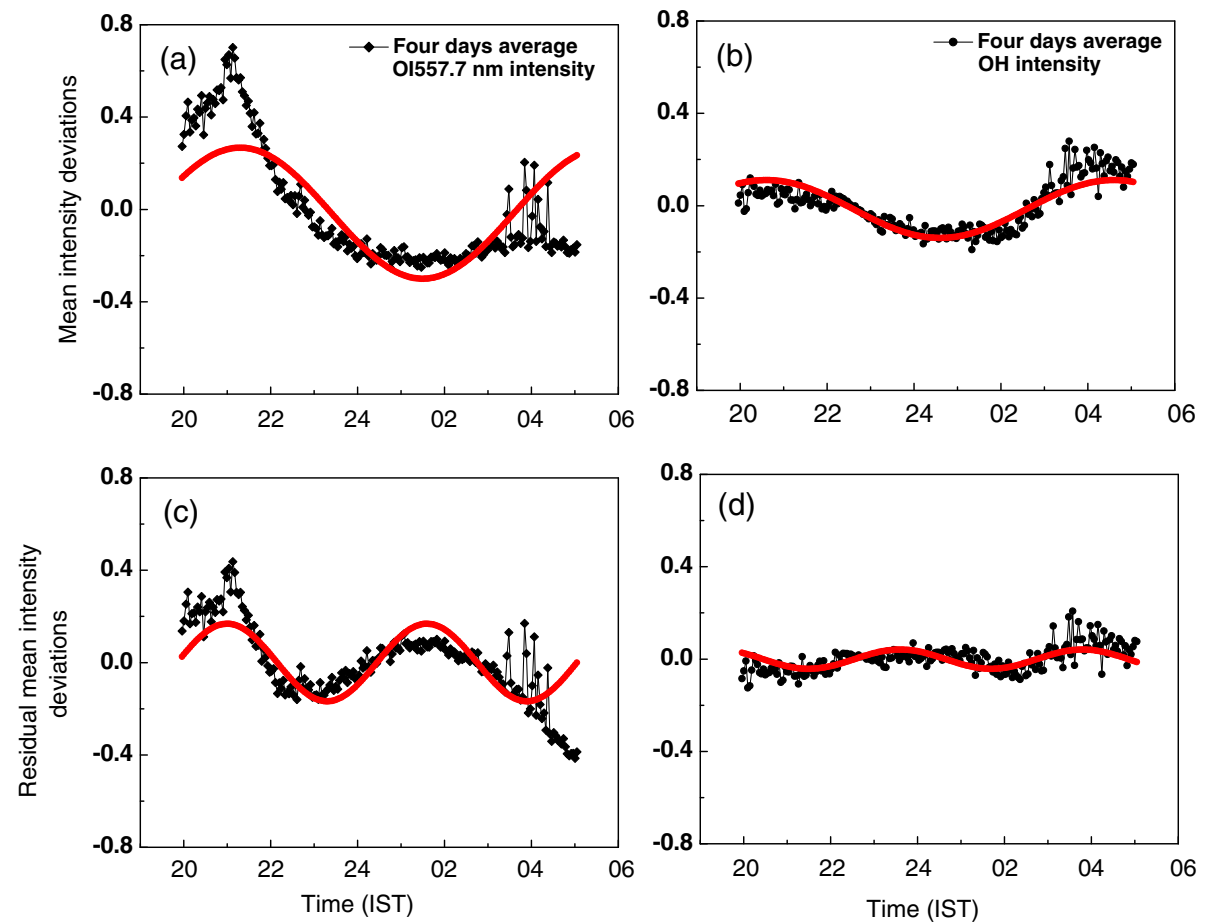

Figure 2. Nocturnal variation of mean intensity deviation of the four days average of OI $557.7 \mathrm{~nm}$ and $\mathrm{OH}$ emissions from 12-15 March 2007 observations are plotted. The upper panels represent the mean deviations in intensity of (a) OI $557.7 \mathrm{~nm}$ and (b) OH emission. The bottom panels represent intensity residuals of (c) OI $557.7 \mathrm{~nm}$ and (d) OH emission. Solid red line curve in each plot shows the result of best-fit cosine model which is used to estimate the dominant wave periodicity, amplitude and phase of waves present in the data. IST is the Indian Standard Time.

April 10-13, 2007; Kolhapur
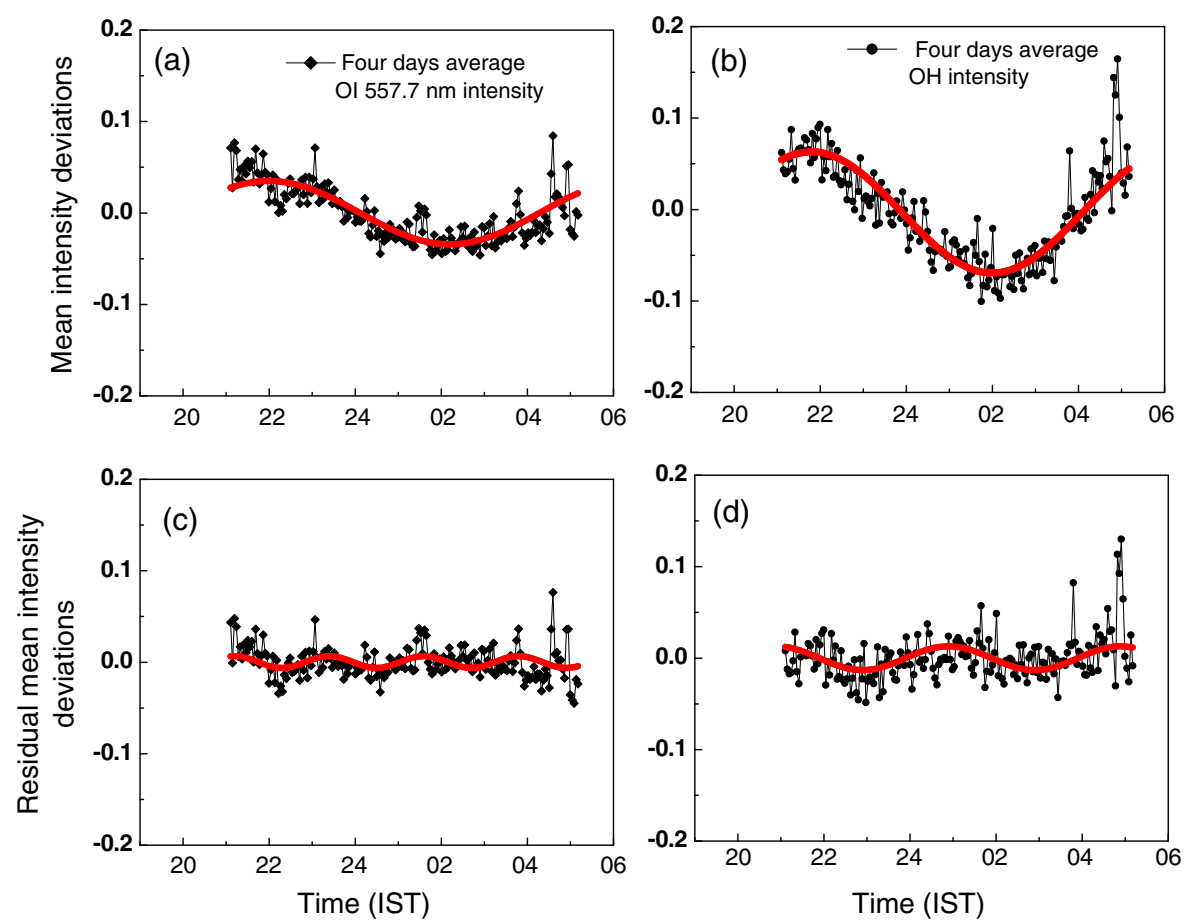

Figure 3. Same as figure 2, but for 10-13 April, 2007. 
February 14 -15, 2004; Kolhapur Harmonic Analysis
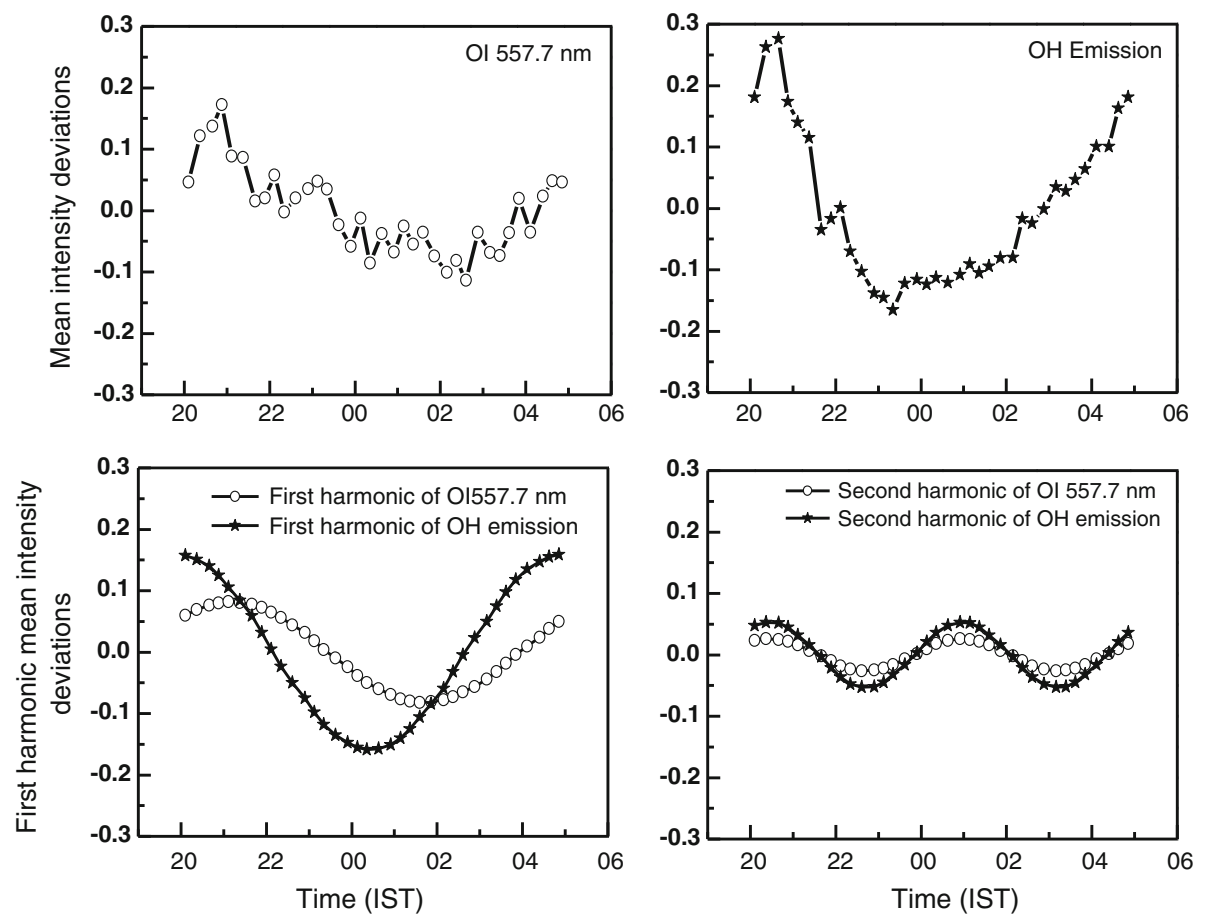

Figure 4. The nocturnal mean intensity deviations of OI $557.7 \mathrm{~nm}$ and $\mathrm{OH}$ emissions for the night of February 14-15, 2004 observed at Kolhapur are plotted in the upper panel along with the contributions of the first and second harmonics (9 and $4.5 \mathrm{hr}$ period) in the lower panels. IST is the Indian Standard Time.

the tidal mode, the convective/shear instability causes wave energy to be transferred from gravity wave to mean flow with consequent changes in the tidal wind amplitude and phase. Recently, clear evidence of planetary wave modes penetrating to $\mathrm{OH}$ layer heights at different times have been observed (French and Klekociuk 2011) which may interact with gravity waves and tidal modes and change their amplitude and phase. However, in the present case we could not find any clear signature of planetary wave. Another possibility could be that the waves may be moving vertically slow in the presence of strong wind. In that case very large vertical wavelength should be observed. The vertical wavelength in the present case lies between 46 and $113 \mathrm{~km}$ (see table 1). The vertical wavelength in the presence of wind is inversely proportional to the difference in phase velocity of the wave and the projection of the background wind on the direction of wave propagation (Akmaev 2001). Thus the vertical wavelength depends on wind direction and magnitude of wind velocity.

Similarly, the mean intensity deviations of OI $557.7 \mathrm{~nm}$ and $\mathrm{OH}$ emissions for the night of February 10-11, 2005 are shown in the upper panels of figure 7 along with the contributions from the first and the second harmonics $(9.4$ and $4.6 \mathrm{hr}$ periods) in the lower panels. The first and the second harmonics show downward phase propagation. Another example of the night airglow mean intensity deviations for March 8-9, 2005 along with the harmonic analysis is shown in figure 8 .

Figure 9 shows the corresponding data for the night of March 10-11, 2005. From the figure we notice that the first harmonics propagate upward and the second harmonics are seen to be opposite to each other. From table 1, we find that the analysis of average mean intensity data yield wave period of the first harmonics between 3 and 12 hours. The wave period of the second harmonics varied between 2 and 4.6 hours. These waves may be attributed to the tidal oscillations.

The vertical wavelength of the wave is computed using the relation (Fagundes et al. 1995):

$$
\lambda(z)=\Delta D \times(360 / \Delta \Phi)
$$

where $\Delta D$ is the separation of the two layers and $\Delta \Phi$ is the phase difference between the waves corresponding to the two emission lines. For waves with periods much larger than the Brunt Vaisala period, $T_{\mathrm{B}}$ (say greater than $1 \mathrm{hr}$ and less than a few hours), the horizontal wave length $\lambda_{\mathrm{x}}$ and the vertical wavelength $\lambda_{z}$ of internal gravity waves are 
Table 1. Three/four days average intensity data are used to determine wave period, time shift and phase shift. These are used to determine vertical velocity and vertical wavelengths which are tabulated below*.

\begin{tabular}{|c|c|c|c|c|c|c|}
\hline Date & $\begin{array}{c}\text { Wave period } \\
557.7(\mathrm{hr})\end{array}$ & $\begin{array}{c}\text { Wave period } \\
\text { OH (hr) }\end{array}$ & $\Delta \mathrm{T}(\min )$ & $\Delta \Phi(\operatorname{deg})$ & $\mathrm{V}(\mathrm{m} / \mathrm{s})$ & $\mathrm{vw}(\mathrm{km})$ \\
\hline January 16-19, 2004 & 8.4 & 7.2 & 42.60 & 35.50 & 4.30 & 111.55 \\
\hline January 16-19, 2004 & 4.4 & 4.0 & 92.40 & 138.60 & 1.98 & 28.57 \\
\hline January $23-30,2004$ & 8.0 & 8.0 & 60.30 & 45.23 & 3.04 & 87.56 \\
\hline January 23-30, 2004 & 3.6 & 3.6 & 75.96 & 126.60 & 2.41 & 31.28 \\
\hline February 13-16, 2004 & 8.0 & 9.6 & 114.18 & 85.5 & 1.66 & 46.32 \\
\hline February 13-16, 2004 & 2.4 & 4.4 & 31.10 & 45.82 & 5.85 & 86.40 \\
\hline February 17-20, 2004 & 8.4 & 12.0 & 74.82 & 52.81 & 2.45 & 74.98 \\
\hline February 17-20, 2004 & 4.4 & 2.8 & 16.26 & 34.84 & 11.28 & 113.65 \\
\hline March 17-22, 2004 & 8.0 & 7.6 & 33.00 & 24.75 & 5.56 & 160.00 \\
\hline March 17-22, 2004 & 3.6 & 2.8 & 29.22 & 62.61 & 6.27 & 63.24 \\
\hline December 18-22, 2004 & 8.0 & 8.0 & 32.40 & 24.30 & 5.66 & 162.96 \\
\hline December 18-22, 2004 & 3.2 & 2.4 & 33.60 & 84.00 & 5.46 & 47.14 \\
\hline December 29-31, 2004 & 12.0 & 12.0 & 49.56 & 24.78 & 3.70 & 159.81 \\
\hline December 29-31, 2004 & 2.8 & 4.0 & 57.00 & 85.50 & 3.22 & 46.32 \\
\hline February $3-5,2005$ & 8.0 & 8.0 & 38.52 & 28.89 & 4.76 & 137.07 \\
\hline February $3-5,2005$ & 4.0 & 4.0 & 61.92 & 92.88 & 2.96 & 42.64 \\
\hline February 8-10, 2005 & 6.2 & 6.2 & 57.90 & 56.03 & 3.17 & 70.67 \\
\hline February 8-10, 2005 & 4.0 & 3.8 & 79.02 & 124.77 & 2.32 & 31.74 \\
\hline March 6-8, 2005 & 6.0 & 6.2 & 45.60 & 42.75 & 4.02 & 92.63 \\
\hline March 6-8, 2005 & 3.2 & 3.4 & 38.40 & 72.00 & 4.77 & 55.00 \\
\hline March 9-11, 2005 & 7.4 & 3.0 & 75.60 & 61.30 & 2.43 & 64.60 \\
\hline March 9-11, 2005 & 4.0 & 2.0 & 88.92 & 133.38 & 2.06 & 29.69 \\
\hline March 12-15, 2007 & 8.4 & 8.0 & 53.40 & 38.14 & 3.43 & 103.82 \\
\hline March 12-15, 2007 & 4.6 & 4.2 & 33.60 & 50.40 & 5.46 & 78.57 \\
\hline April 10-13, 2007 & 8.4 & 8.4 & 52.80 & 39.60 & 3.47 & 100.00 \\
\hline April 10-13, 2007 & 2.2 & 4.0 & 49.80 & 71.14 & 3.68 & 55.66 \\
\hline
\end{tabular}

*All the parameters have been calculated from the method of Fagundes et al. (1995).

vw - Vertical wavelength.

February 15 -16, 2004; Kolhapur

Harmonic analysis
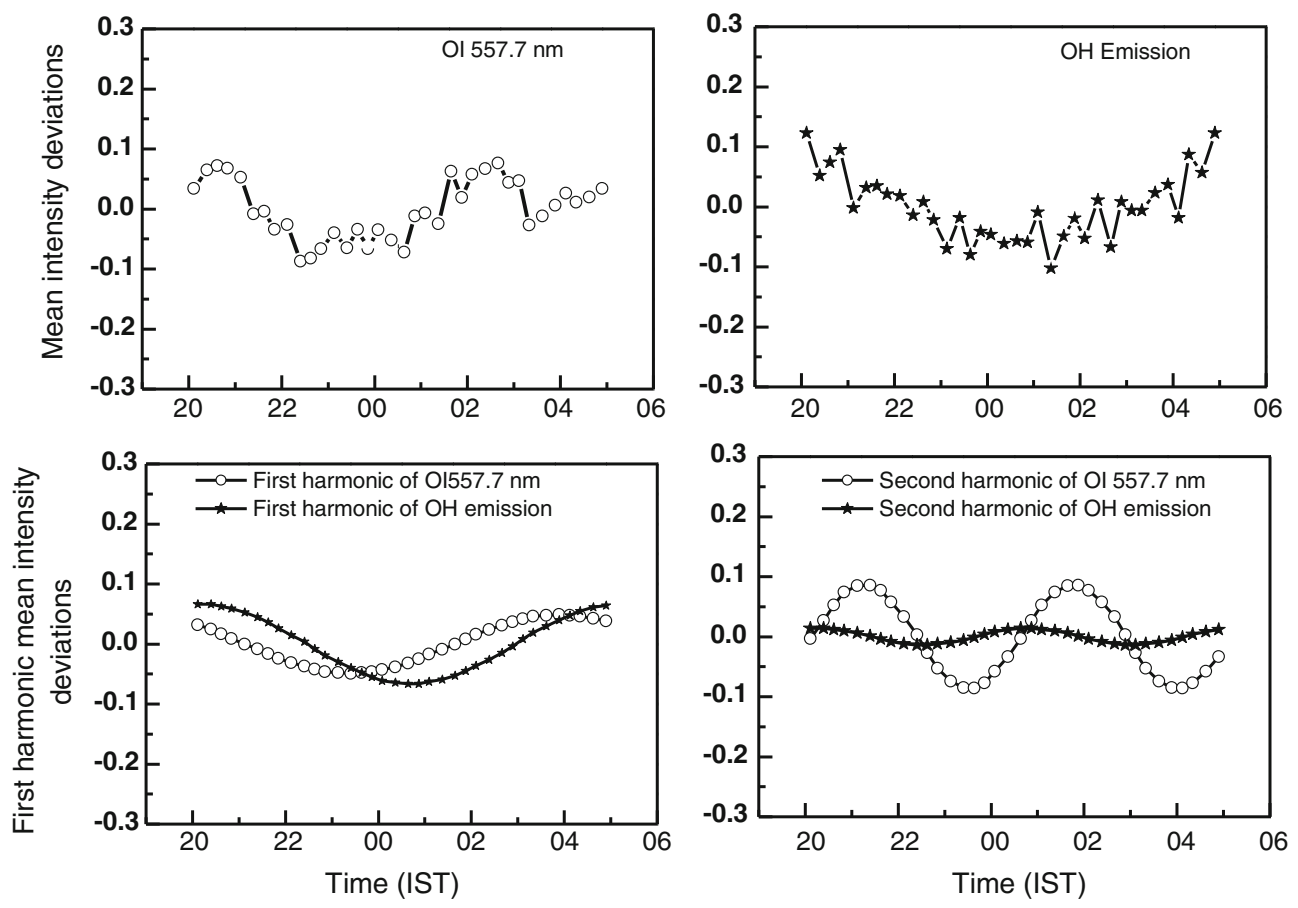

Figure 5. Same as figure 4, but for February 15-16, 2004. 
February 17 -18, 2004; Kolhapur

Harmonic analysis
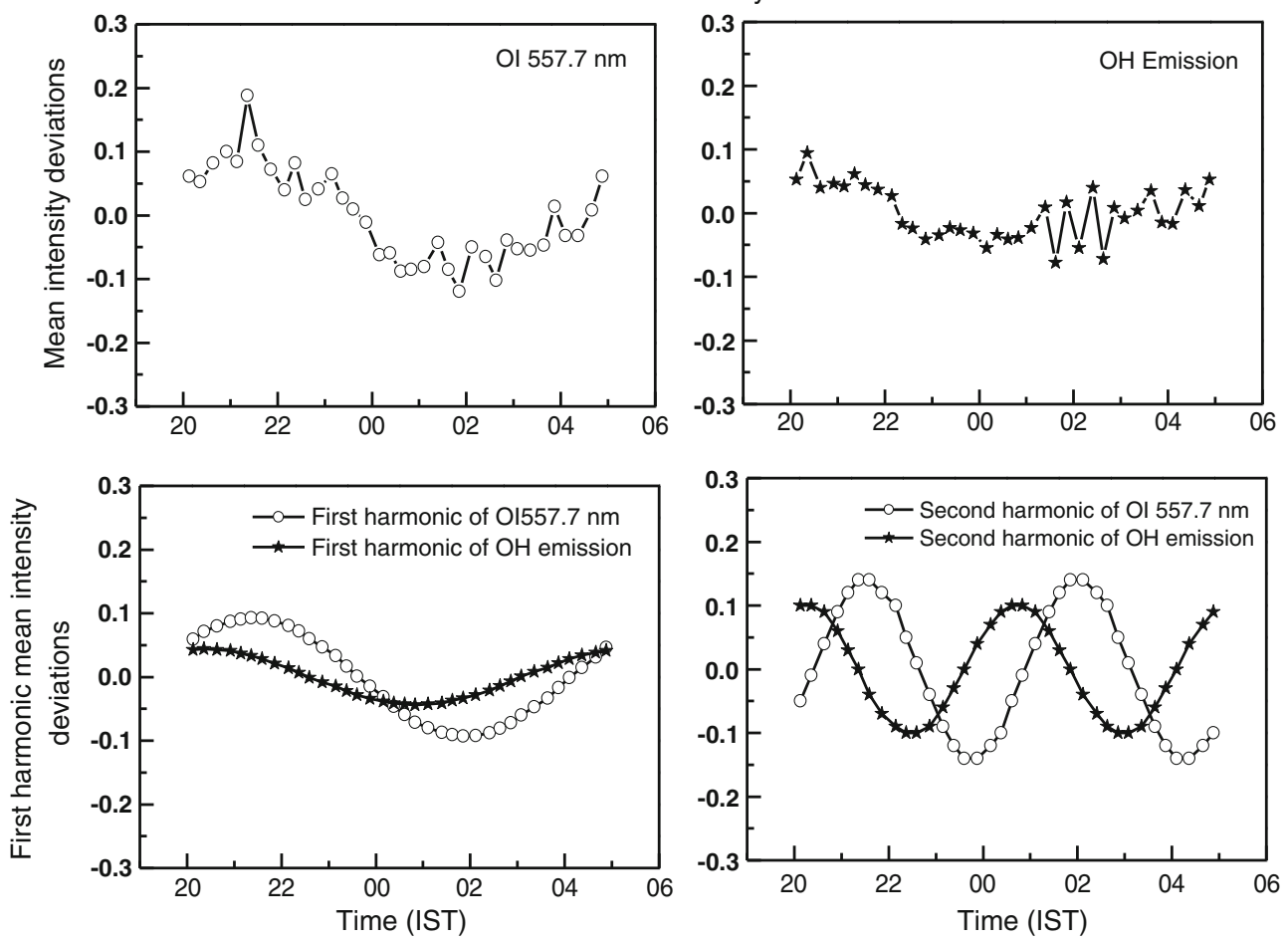

Figure 6. Same as figure 4, but for February 17-18, 2004.

February 10 -11, 2005; Kolhapur

Harmonic analysis
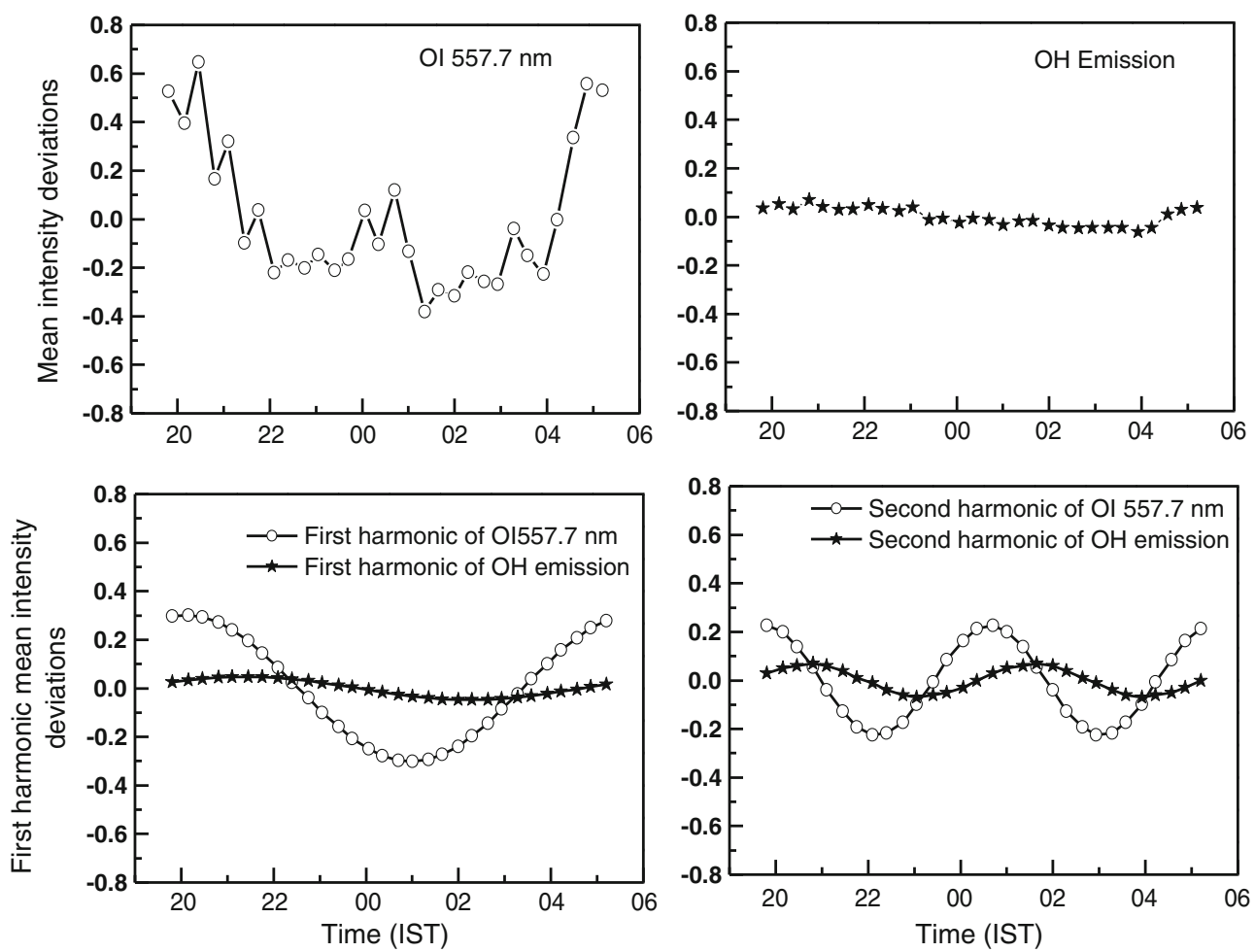

Figure 7. Same as figure 4, but for February 10-11, 2005. 
March 08 - 09, 2005; Kolhapur

Harmonic analysis
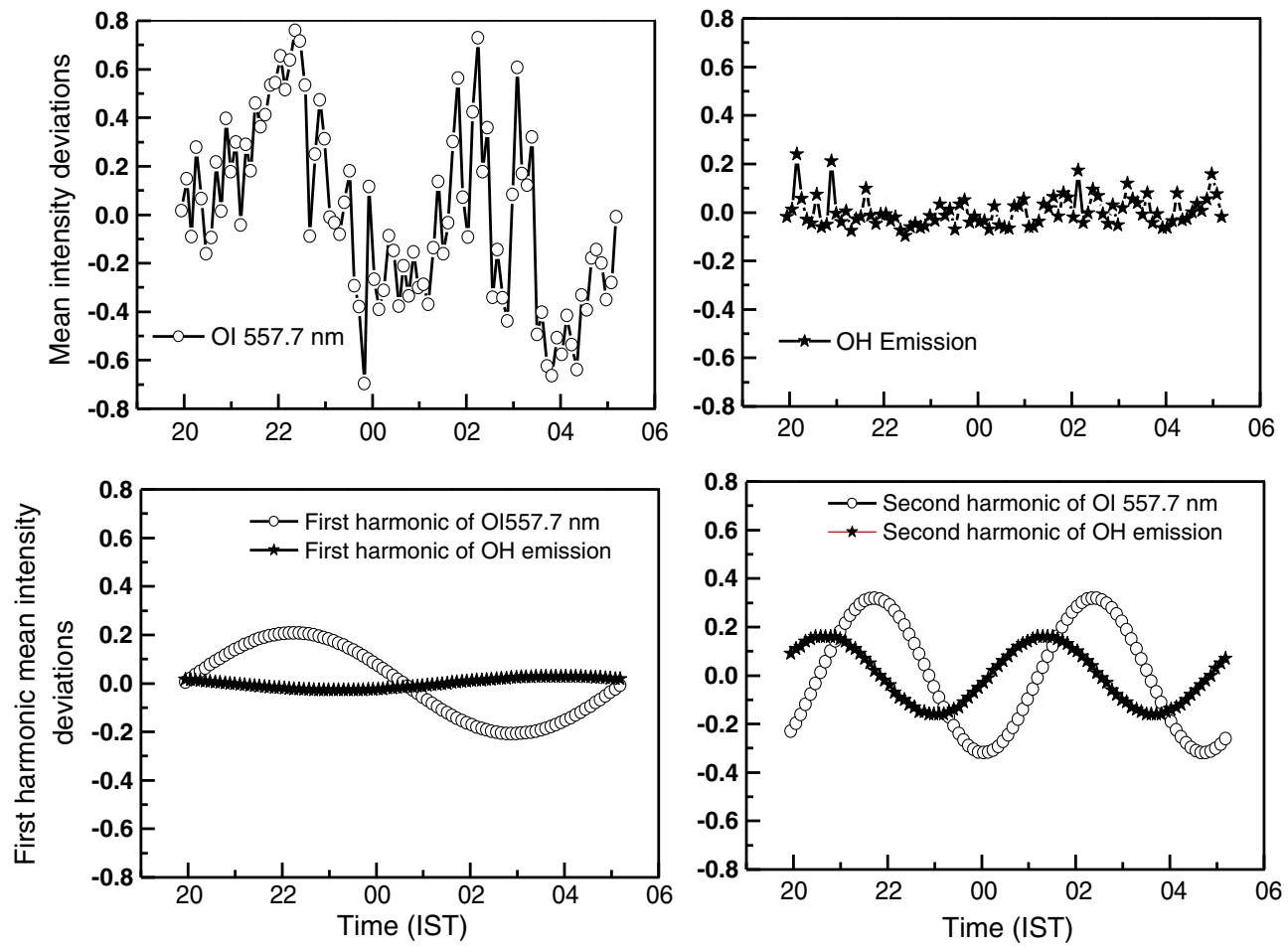

Figure 8. Same as figure 4, but for March 8-9, 2005.

March 10 - 11, 2005; Kolhapur

Harmonic analysis
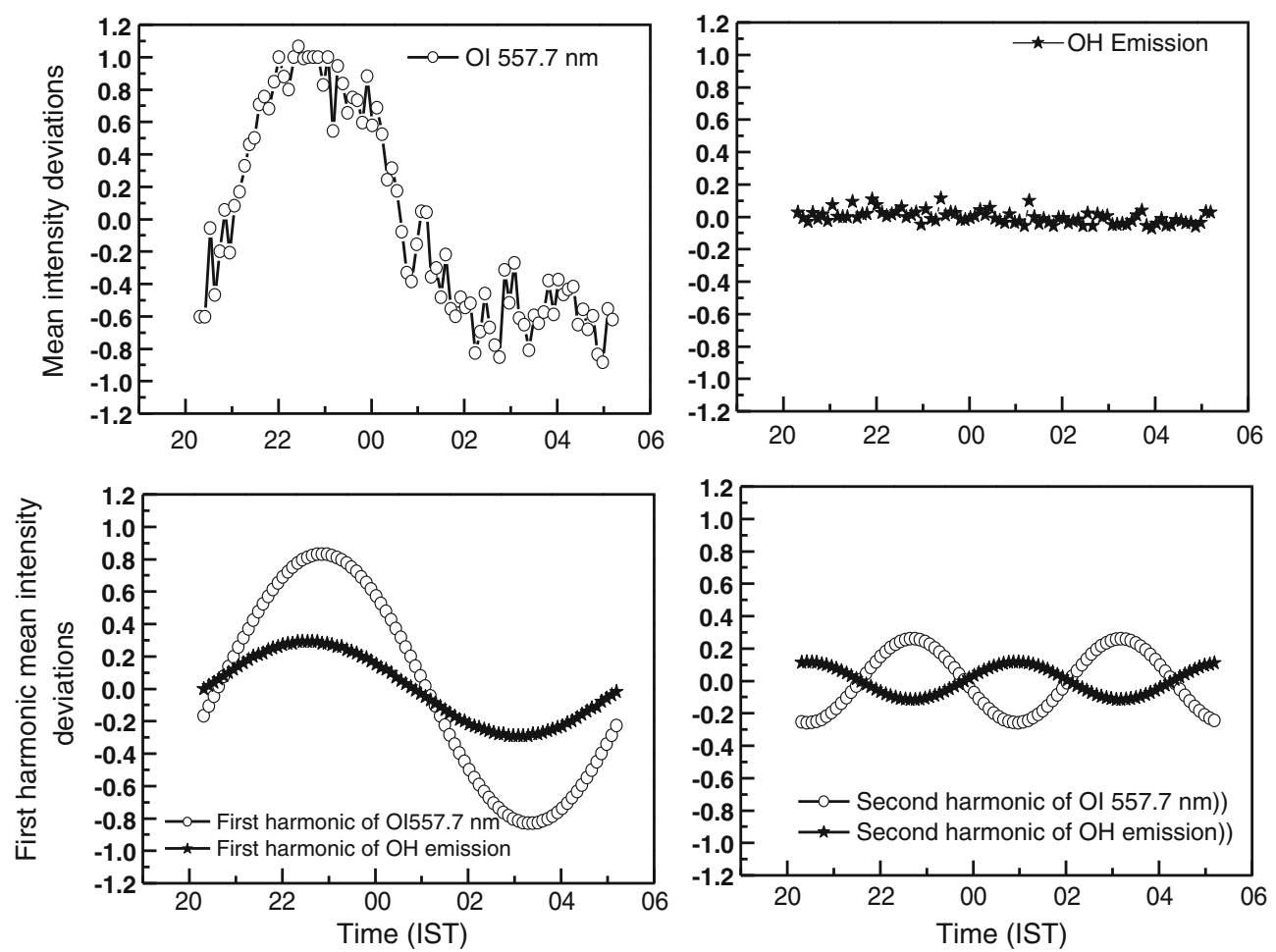

Figure 9. Same as figure 4, but for March 10-11, 2005. 
related through the relation (Hines 1960; Fagundes et al. 1995)

$$
\frac{\lambda_{\mathrm{x}}}{\lambda_{\mathrm{z}}}=\frac{T_{\mathrm{W}}}{T_{\mathrm{B}}}
$$

where $T_{\mathrm{W}}$ is the wave period. This simple relation changes for very long and very short period waves (Fagundes et al. 1995). The time period ( $T$ in $\min$ ) and phase difference $|\Delta \varnothing|$ obtained from the cross correlation analysis of the two emission lines, OI $557.7 \mathrm{~nm}$ and $\mathrm{OH}(7,2)$ have been used to compute the vertical wavelength which varies between approximately 28.7 and $113.6 \mathrm{~km}$ (short period, S) wave propagation and it varies between 46.3 and $160.9 \mathrm{~km}$ (long period, L) wave propagation. Values of the vertical wavelength show significant day-to-day variability $(\sim 28.5-160.9 \mathrm{~km})$ with an average value of $\sim 54.6 \mathrm{~km}$ for the short period waves and $\sim 105 \mathrm{~km}$ for the long period wave. The source of these waves may be in the troposphere from which the gravity waves propagate upward in the middle atmosphere. However, in situ excitation at the airglow altitudes or ducting in the upper middle atmosphere has also been suggested by observations (Isler et al. 1997; Hecht et al. 2009) and numerical modelling (Fritts et al. 1997; Hertzog et al. 2002).

The vertical wavelength obtained by several investigators matches more or less with our observed values. Reddi and Ramkumar (1997) reported significantly higher values of the vertical wavelength $(>100 \mathrm{~km})$ with meteor wind observations at Trivandrum. Taori et al. (2005) obtained a large variability of vertical wavelength $(\sim 26-$ $110 \mathrm{~km}$ ) with the mean value $\sim 90 \mathrm{~km}$ which resembles very well with our results. Contrary to the large variability in the vertical wavelength of tidal oscillations, Deepa et al. (2006) using Meteor Radar data collected at Trivandrum showed the vertical wavelength of the terdiurnal tide $\sim 16-$ $50 \mathrm{~km}$ during various seasons with the maximum amplitude at $95 \mathrm{~km}$ altitude, a result consistent with the Meteor Radar measurement at the high latitudes (Wu et al. 2005). These results clearly show that airglow emission data yield the vertical wavelength consistently higher values than those derived from the Meteor Radar measurements. To resolve this paradox, simultaneous measurements using both the techniques are recommended. Moreover, in the analysis of airglow data one considers emission of a particular line to come from a fixed altitude, which itself may vary due to variation in gas compositions caused by various factors.

We have also computed the correlation coefficients $(r)$ between OI $557.7 \mathrm{~nm}$ and $\mathrm{OH}(7,2)$ emission intensities for the short and the long wave periods observed on 54 nights during the period of 2004-2007. It is noted that there is a high degree of correlation between the two sets of data of two emission lines. The correlation coefficient varies between 0.763 and 0.872 . The high values of correlation also predict very high values of the vertical wavelength.

The estimated phase velocities for the short period waves between $\mathrm{OH}$ and $\mathrm{OI} 557.7 \mathrm{~nm}$ layers vary between 2.0 and $12.0 \mathrm{~m} / \mathrm{s}$ and the time lag varies between 16.26 to $92.4 \mathrm{~min}$. The long period wave phase velocities vary between 1.95 and $18.9 \mathrm{~m} / \mathrm{s}$ and time lag varies between 32.4 and $114.18 \mathrm{~min}$ of the two emissions OI $557.7 \mathrm{~nm}$ and $\mathrm{OH}$. The data was dominated by a terdiurnal tidelike wave. From table 1, it is noticed that the average vertical velocity of 10 diurnal oscillations is $3.4 \mathrm{~m} / \mathrm{s}$ in $2004,3.6 \mathrm{~m} / \mathrm{s}$ in 2005 and $3.4 \mathrm{~m} / \mathrm{s}$ in 2007. The corresponding average vertical wavelength for the years 2004, 2005 and 2007 is 107.2, 100.9 and $101.9 \mathrm{~km}$, respectively. Thus the average vertical velocity and wavelength does not show appreciable variation on yearly basis.

\section{Tidal influences in airglow}

Figure 10(a, b), shows the cosine fit curve of OI $557.7 \mathrm{~nm}$ and $\mathrm{OH}(7,2)$ emissions for the night of February 14-15, 2004. Solid line shows the best fit curve along with the $15 \mathrm{~min}$ running average of the mean airglow intensity deviations. It is seen that the period of OI $557.7 \mathrm{~nm}$ intensity variation is $\sim 6 \mathrm{hr}$ and $\mathrm{OH}$ emission period is $\sim 8 \mathrm{hr}$. The residuals of mean intensity deviations shown in the lower panels $(c, d)$, which are consistently spread around zero yielding the validation of cosine model. Periodicity of tidal wave at $\mathrm{OH}$ emission is more dominant than OI $557.7 \mathrm{~nm}$ emission. The same results for February 15-16, 2004 are shown in figure 11 where the solid line shows the cosine fit curve. The period of OI $557.7 \mathrm{~nm}$ mean intensity deviation is $\sim 4.5 \mathrm{hr}$ and for the $\mathrm{OH}$ emission it is $\sim 8 \mathrm{hr}$. The residuals are plotted in the lower panels $(c, d)$. From the figure it is clearly seen the presence of small period waves in OI $557.7 \mathrm{~nm}$ data, which is also evident from the plot of residuals. Apart from tidal oscillations, short period oscillation observed in the OI $557.7 \mathrm{~nm}$ emissions could be due to gravity wave. Figure $12(\mathrm{a}, \mathrm{b})$ also shows another example of terdiurnal oscillations in the OI $557.7 \mathrm{~nm}$ and $\mathrm{OH}$ emissions data observed on February 19-20, 2004.

Analyzing nightglow emission data, we have shown the presence of terdiurnal $(8 \mathrm{hr})$ tides during the 
February 14 - 15, 2004; Kolhapur
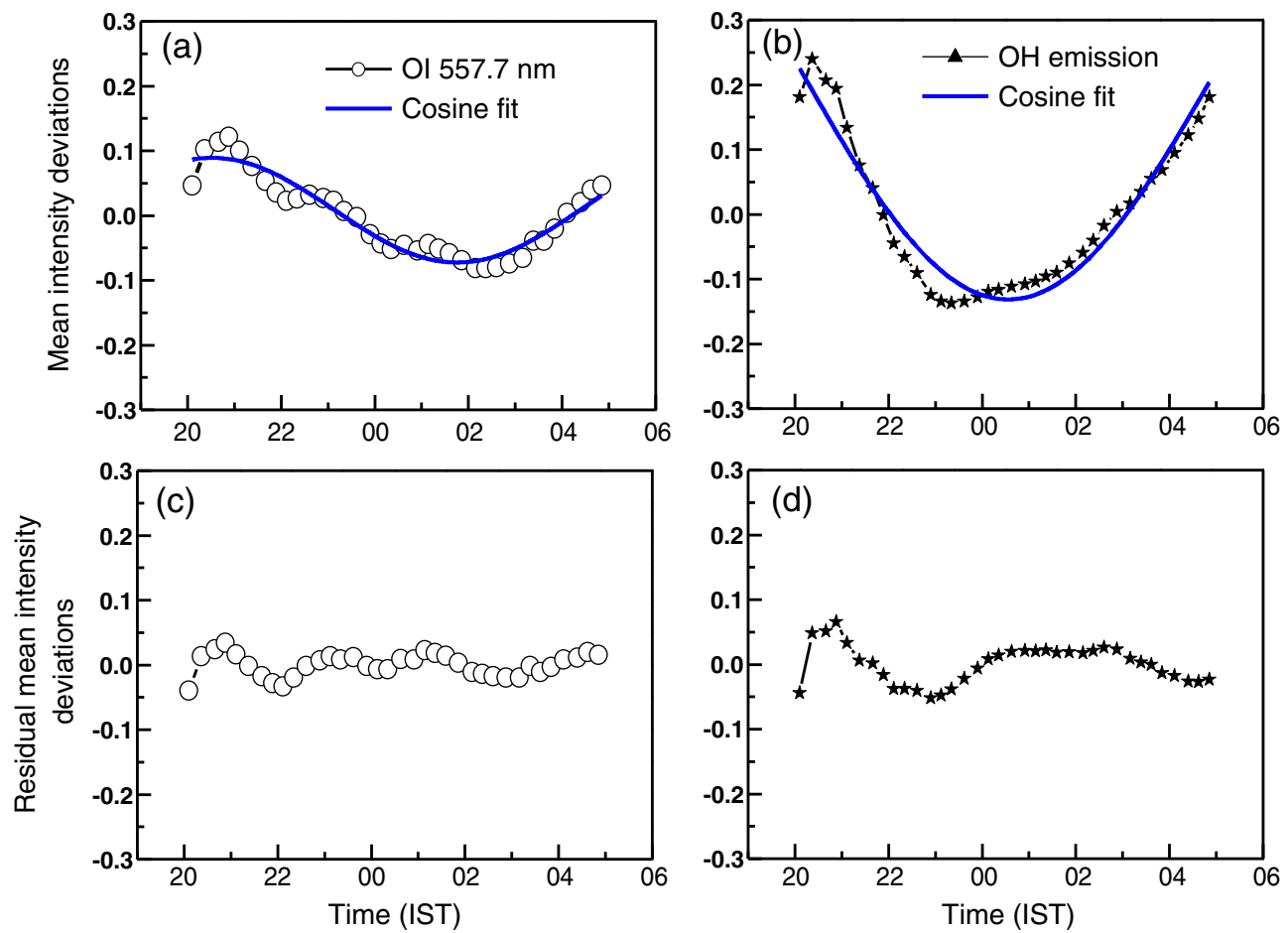

Figure 10. Nocturnal variation of mean intensity deviations in OI $557.7 \mathrm{~nm}$ and $\mathrm{OH}$ emissions for the night of February 14-15, 2004 at Kolhapur are presented. The upper panels represent the mean deviations in intensity of (a) OI 557.7 nm (b) $\mathrm{OH}$ emissions. Solid blue line curves in (a) and (b) plots show the result of best cosine fit curve. Long period tide-like oscillation is evident in the data with periodicity of about $6 \mathrm{hr}$ in OI $557.7 \mathrm{~nm}$ and $8 \mathrm{hr}$ in OH emissions. The airglow intensity residuals are plotted in the lower panel $(\mathbf{c}, \mathbf{d})$. IST is the Indian Standard Time.

February 15-16, 2004 ; Kolhapur
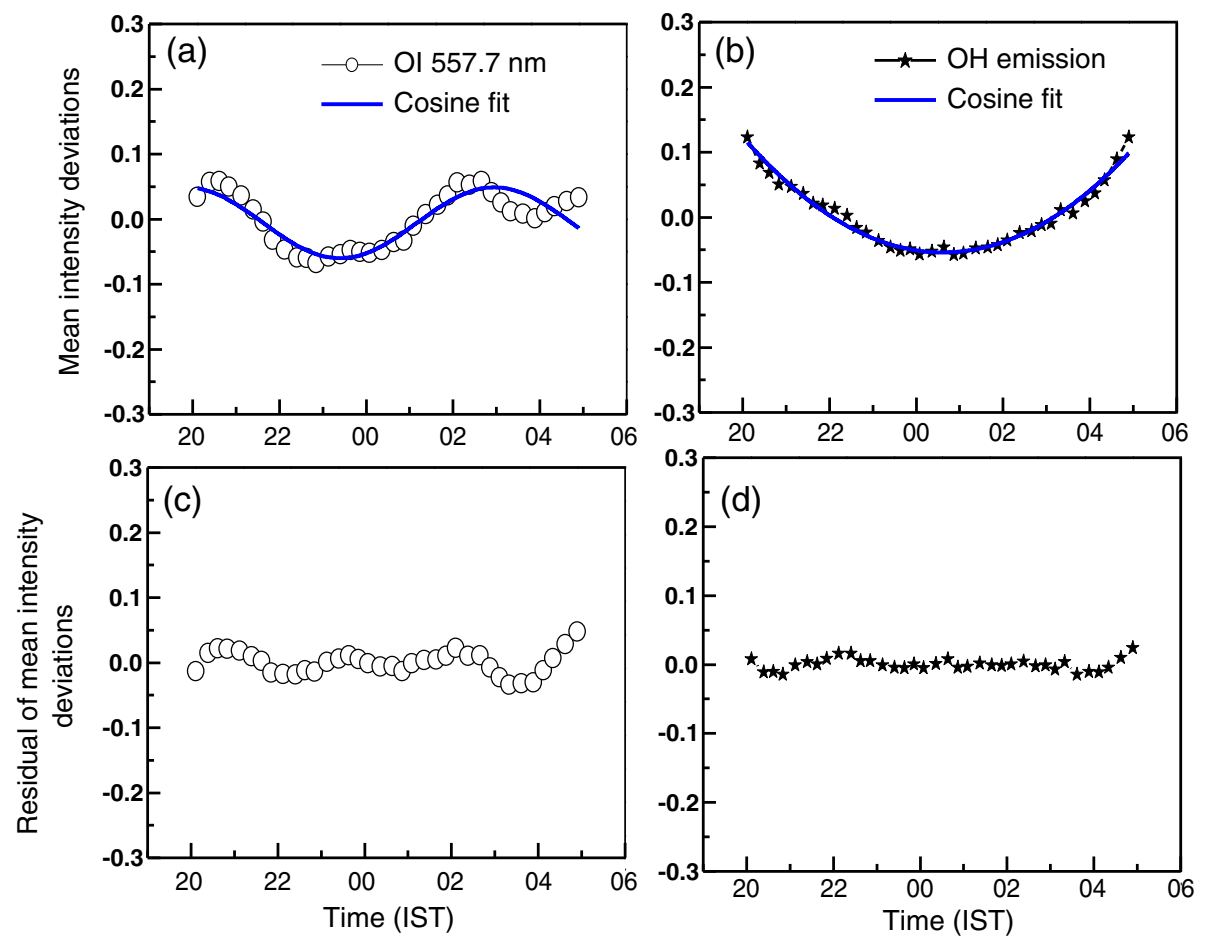

Figure 11. Same as figure 10, but for February 15-16, 2004. 

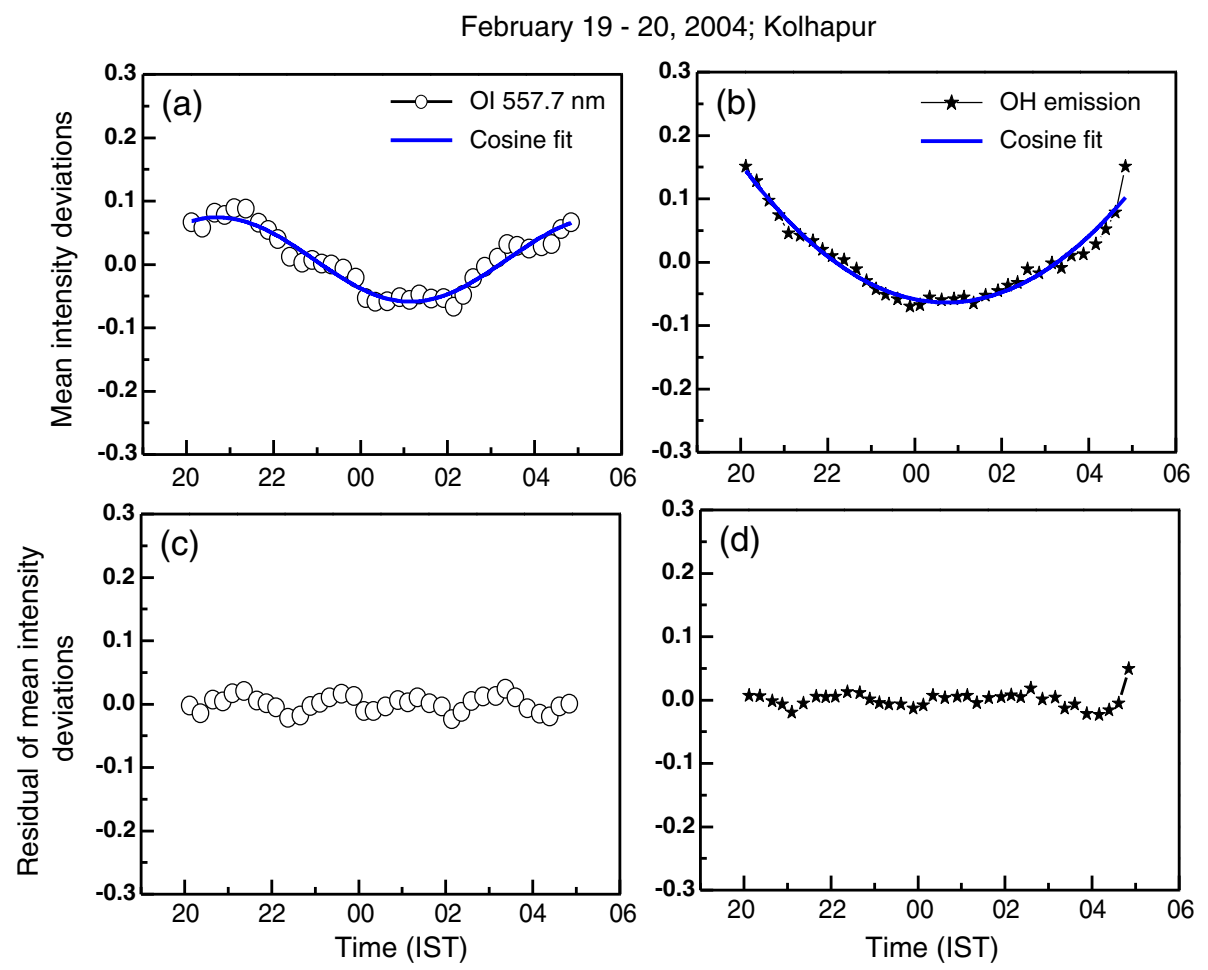

Figure 12. Same as figure 10, but for February 19-20, 2004.

month of February, 2004. The observed difference in the periodicity of $\mathrm{OH}$ and OI $557.7 \mathrm{~nm}$ emissions may be due to the wave-mean wind interaction between these two altitudes. It is observed from the plots that $\mathrm{OH}$ is having higher wave activity during the observation period than OI emissions. Thayaparan (1997) reported significant contribution of $8 \mathrm{hr}$ tide during the spring and winter months and less contribution during the summer and fall months. At mid-latitude, the amplitude of $8 \mathrm{hr}$ tides maximizes during spring and fall months (Smith et al. 2000). Taori and Taylor (2010) reported dominance of $8 \mathrm{hr}$ tides at the low latitude station Maui, Hawai during the late winter time, which is close to our findings. Using satellite based wind observations, Zhao et al. (2005) showed a quite different seasonal pattern of $8 \mathrm{hr}$ tides.

The simultaneous measurements of various airglow emissions emanating from different altitudes in the atmosphere on a given night provide information about the vertical propagation of waves through the region. In these preliminary results we have shown the presence of waves of different periods (table 1) including the determinant terdiurnal tidal modes. Waves with periods of a few hours could be gravity waves. Multispectral mesosphere nightglow emissions have reported gravity waves with periods of a few hours propagating through the upper atmosphere in the low latitude regions (Molina et al. 1985; Takahashi et al. 1985;
Fagundes et al. 1995). Taori and Taylor (2010) have also shown the presence of terdiurnal long period waves and short period waves in the mesospheric $\mathrm{O}_{2}$ airglow emissions. The wave growth or damping during propagation could not be studied due to the limited availability of data and the absence of multi-instrument observations. The vertical upward propagation of wave suggests that the source region may lie in the lower atmosphere, i.e., in the troposphere or the stratosphere. The source of these waves could be: (a) tidal oscillation caused by absorption of solar radiation in the lower atmosphere, (b) gravity waves generated by different processes in the troposphere, (c) wave-wave or wave-tide interactions and development of instabilities leading to generation and amplification of waves, and (d) interaction between different modes may also give rise to other modes. For example, interaction between semi-diurnal and diurnal tides may result into the generation of terdiurnal waves (Taylor et al. 1999). The interaction of tidal wave with gravity waves also generates new wave modes (Thayaparan et al. 1995). Nonlinear interactions between the stationary planetary waves and migrating tides may also lead to the diurnal tide (Hagan and Roble 2001) and the semidiurnal tides (Angelats i Coll and Forbes 2002). Using modelling studies (Roble and Shepherd 1997; Yudin et al. 1998; Zhang et al. 2001), the perturbation in airglow emission have also been linked to tidal oscillations. 


\section{Summary and conclusions}

The analysis of night time airglow emission lines $\mathrm{OH}(7,2)$ and $\mathrm{OI} 557.7 \mathrm{~nm}$ showed the presence of terdiurnal and other sub-harmonics of solar tidal oscillations. The observed short period waves may be the manifestation of tidal wave interactions amongst themselves or their interactions with winds, gravity waves, planetary waves, etc. In the present analysis, direction of propagation, wavelength and wave periods are determined. The waves with wave periods of a few hours usually should have origin in the lower atmosphere and wave propagation direction upward. In a few cases we did observe downward wave propagation. Such cases may be the result of local strong wind effect which modified the amplitude and phase of the waves. In the absence of wind data, it is difficult to understand the propagation mechanism. More data analysis and simulation studies with different direction and magnitude of wind are required to resolve this issue. Some of the results are:

- The vertical velocities of the long and short period waves propagating between $\mathrm{OH}$ and $\mathrm{OI}$ $557.7 \mathrm{~nm}$ layers vary randomly on day-to-day basis. On some days, velocity of the long period wave is large and on the other day velocity of the short period wave is large. No clear cut picture could be obtained. Similar results were obtained in 2004, 2005 and 2007.

- The $8 \mathrm{hr}$ terdiurnal component of atmospheric tides are often present in $\mathrm{OH}(7,2)$, and $\mathrm{OI}$ $557.7 \mathrm{~nm}$ emissions. The average velocity and wavelength did not show appreciable change during the observation period from 2004 to 2007. The observed difference in periodicity of the wave may be due to the wave mean wind interactions between the two airglow layers.

- Good correlations are found between the $\mathrm{OH}$ and OI $557.7 \mathrm{~nm}$ emission intensity on most of the nights for the short period and the long period variations.

- The wave--wave interactions could be seen in $\mathrm{OH}$ emission layer.

In the present study, we have taken the height of $\mathrm{OH}$ and $\mathrm{OI}$ emission layer to be 86 and $97 \mathrm{~km}$, respectively, which may change from time to time due to altitude variation in atmospheric constituents. The variation will change the derived wave parameters. In the present study we could not decipher the origin of short period waves. Additional observations using different techniques are required to explain the wavy structures observed in the airglow emission data. Hence, further long term multi-instrument observations (using ground-based and space-based), theoretical studies and modelling are required to deal with this less explored and the most important region of the atmosphere.

\section{Acknowledgments}

RNG thanks the Department of Science and Technology (DST), Government of India, New Delhi for providing financial assistance to carry out the research in the upper atmosphere under the scientific collaboration program between IIG, Navi Mumbai and Shivaji University, Kolhapur and also thanks the Director, IIG Mumbai for constant encouragement and extending necessary facilities. This work is partially supported by the collaboration with IITM Pune, BHU Varanasi and Kolhapur under the CAWSES program. DS thanks Prof. B N Goswami, Director, IITM for his kind support. The authors wish to thank the anonymous reviewers for their critical comments which helped to improve the paper.

\section{References}

Abreu V J and Yee J H 1989 Diurnal and seasonal variation of the nighttime $\mathrm{OH}(8-3)$ emission at low latitudes; J. Geophys. Res. 94 11,949-11,957.

Akmaev R A 2001 Seasonal variations of the terdiurnal tide in the mesosphere and lower thermosphere: A model study; Geophys. Res. Lett. 28 3817-3820, doi: 10.1029/2001GL013002.

Angelats i Coll M and Forbes J M 2002 Nonlinear interactions in the upper atmosphere: The $\mathrm{s}=1$ and $\mathrm{s}=3$ nonmigrating semidiurnal tides; J. Geophys. Res. 107 1157.

Brown B G, Bullock R R, Davis C A, Gotway J H, Chapman M B, Takacs A, Gilleland E and Manning K 2004 New Verification Approaches for Convective Weather Forecasts, Proceedings of the 22nd Conference on Severe Local Storms, October 2004, Hyannis, MA.

Burrage M D, Wu D L, Skinner W R, Ortland D A and Hays P B 1995 Latitude and seasonal dependence of the semidiurnal tide observed by the high resolution Doppler imager; J. Geophys. Res. 100 11,313-11,322.

Chapman S and Lindzen R S 1970 Atmospheric tides, D. Reidel Press, Dordrecht, Holland, 200p.

Dao P D, Farley R, Tao X and Gardner C S 1995 Lidar observations of the temperature profile between 25 and $103 \mathrm{~km}$ : Evidence of tidal perturbation; Geophys. Res. Lett. 22 2825-2828.

Das S K, Taori A and Jayaraman A 2011 On the role of dust storms in triggering atmospheric gravity waves observed in the middle atmosphere; Ann. Geophys. 29 1647-1654, doi: 10.5194/angeo-29-1647-2011.

Daubechies I 1988 Orthonormal bases of compactly supported wavelets; Commun. Pure. Appl. Math. 41 909996.

Deepa V, Ramkumar G, Antonita T M, Kumar K K and Sasi M N 2006 Vertical propagation characteristics and seasonal variability of tidal wind oscillations in the MLT region over Trivandrum $\left(8.5^{\circ} \mathrm{N}, 77^{\circ} \mathrm{E}\right)$ : First results from SKiYMET Meteor Radar; Ann. Geophys. 24 1-13. 
Eckermann S D and Preusse P 1999 Global measurements of stratospheric mountain waves from space; Science $\mathbf{2 8 6}$ 1534-1537.

Fadnavis S, Siingh Devendraa and Singh R P 2009 Mesospheric inversion layer and sprites; J. Geophys. Res. 112 D15305, doi: 10.10292008JD008379.

Fagundes P R, Takahashi H, Sahai Y and Gobbi D 1995 Observations of gravity waves from multi-spectral mesospheric nightglow emissions observed at $23^{\circ} \mathrm{S} ;$ J. Atmos. Terr. Phys. 57 395-405.

Forbes J M, Zhang X, Angelats i Coll M and Keating G M 2004 Nonmigrating tides in the thermosphere of Mars: A quasi-empirical description; Adv. Space Res. 34 1690-1695.

French W J R and Klekociuk A R 2011 Long-term trends in Antarctic winter hydroxyl temperatures; J. Geophys. Res. 116 D00P09, doi: 10.1029/2011JD015731.

Fritts D C and Alexander M J 2003 Gravity wave dynamics and effects in the middle atmosphere; Rev. Geophys. 41(1) 1003, doi: 10.1029/2001RG000106.

Fritts D C, Isler J R, Hecht J H, Walterscheid R L and Andreassen $\varnothing 1997$ Wave breaking signatures in sodium densities and $\mathrm{OH}$ nightglow, part II, Simulation of wave and instability structures; J. Geophys. Res. 102 66696684 .

Hagan M E and Roble R G 2001 Modeling diurnal tidal variability with the NCAR TIME-GCM; J. Geophys. Res. 106 24,869-24,882.

Hecht J H, Walterscheid R L, Hickey M and Franke S 2001 Climatology and modeling of quasi-monochromatic atmospheric gravity waves observed over Urbana Illinois; J. Geophys. Res. 106(D6) 5181-5195.

Hecht J H, Kovalam S, May P T, Mills G, Vincent R A, Walterscheid R L and Woithe J 2004 Airglow imager observations of atmospheric gravity waves at Alice Springs and Adelaide, Australia during the Darwin Area Wave Experiment (DAWEX); J. Geophys. Res. 109 D20S05, doi: 10.1029/2004JD004697.

Hecht J H et al. 2009 Imaging of atmospheric gravity waves in the stratosphere and upper mesosphere using satellite and ground-based observations over Australia during the TWPICE campaign; J. Geophys. Res. 114 D18123, doi: 10.1029/2008JD011259.

Hertzog A, Vial F, Dörnbrack A, Eckermann S D, Knudsen B M and Pommereau J-P 2002 In situ observations of gravity waves and comparisons with numerical simulations during the SOLVE/THESEO 2000 campaign; J. Geophys. Res. 107(D20), doi: 10.1029/ 2001JD001025.

Hines C O 1960 Internal atmospheric gravity waves at ionospheric heights; Can. J. Phys. 38 1441-1481.

Hines C O and Tarasick D W 1987 On the detection and utilization of gravity waves in airglow studies; Planet. Space Sci. 35 851-866.

Isler J R, Taylor M J and Fritts D C 1997 Observational evidence of wave ducting and evanescence in the mesosphere; J. Geophys. Res. 102 26,301-26,313.

Krassovsky V I 1972 Infrasonic variation of OH emission in the upper atmosphere; Ann. Geophys. 28739 746.

Li F, Liu A Z, Swenson G R, Hecht J H and Robinson W A 2005a Observations of gravity wave breakdown into ripples associated with dynamical instabilities; J. Geophys. Res. 110 D09S11, doi: 10.1029/2004JD004849.

Li T, She C Y, Williams B P, Yuan T, Collins R L, Kieffaber L M and Peterson A W 2005b Concurrent OH imager and sodium temperature/wind lidar observation of localized ripples over northern Colorado; J. Geophys. Res. 110 D13110, doi: 10.1029/2004JD004885.
Liu H-L, Li T, She C-Y, Oberheide J, Wu Q, Hagan M E, $\mathrm{Xu}$ J, Roble R G, Mlynczak M G and Russell J M III 2007 Comparative study of short term tidal variability; $J$. Geophys. Res. 112 D13108, doi: 10.1029/2007JD008542. Lopez-Gonzalez M J, Rodriguez E, Shepherd G G, Sargoytchev S, Shepherd M G, Aushev V M, Brown S, Garcia-Comas M and Wiens R H 2005 Tidal variations of $\mathrm{O}_{2}$ atmospheric and $\mathrm{OH}(6-2)$ airglow and temperature at mid-latitudes from SATI observations; Ann. Geophys. 23 3579-3590.

Manson A H, Meek C, Hagan M E, Zhang X and Luo Y 2004 Global distributions of diurnal and semidiurnal tides: Observations from HRDI-UARS of the MLT region and comparisons with GSWM-02 (migrating, non migrating components); Ann. Geophys. 22 1529-1548.

McLandress C, Shepherd G G, Solheim B H, Burrage M D, Hays P B and Skinner W R 1996 Combined mesosphere/thermosphere winds using WINDII and HRDI data from the upper atmosphere research satellite; J. Geophys. Res. 101 10,441-10,453, doi: 10.1029/95JD01706.

Meriwether J W, Gao X, Wickwar V, Wilkerson T, Beissner K, Collins S and Hagan M 1998 Observed coupling of the mesospheric inversion layer to the thermal structure; Geophys. Res. Lett. 25 1479-1482.

Molina A Lopez-Puestas, Lopez-Moreno J J and Rodrigo R 1985 Gravity waves from five simultaneous emissions: $\mathrm{OH}(6-2), \mathrm{NaD}, \mathrm{O}_{2}\left({ }^{1} \Sigma\right), \mathrm{OI}-557.7 \mathrm{~nm}$, and the visible continuum; Can. J. Phys. 63 592-596.

Mukherjee G K 2003 Studies of equatorial F-region depletions and dynamics using multiple wavelength nightglow imaging; J. Atmos. Solar-Terr. Phys. 65 379-390.

Nakamura T, Higashikawa A, Tsuda T and Matsushita Y 1999 Seasonal variations of gravity wave structures in $\mathrm{OH}$ airglow with a CCD imager at Shigaraki; Earth Planets Space 51 897-906.

Narayanan L, Gurubaran V S and Emperumal K 2010 Airglow imaging observations of small-scale structures driven by convective instability in the upper mesosphere over Tirunelveli $\left(8.7^{\circ} \mathrm{N}\right)$; J. Geophys. Res. 115 D19119, doi: 10.1029/2009JD012937.

Pautet P-D, Taylor M J, Liu A Z and Swenson G R 2005 Climatology of shot-period gravity waves observed over northern Australia during the Darwin Area Wave Experiment (DAWEX) and their dominant source regions; $J$. Geophys. Res. 110 D03S90, doi: 10.1029/2004JD004954.

Reddi C R and Ramkumar G 1997 Climatologies of tidal winds in the radio-meteor region over Trivandrum $\left(8^{\circ} \mathrm{N}\right)$; J. Atmos. Sol. Terr. Phys. 59 1757-1777.

Roble R G and Shepherd G G 1997 An analysis of wind imaging interferometer observations of $\mathrm{O}(1 \mathrm{~S})$ equatorial emission rates using the thermosphere-ionosphere mesosphere-electrodynamics general circulation model; J. Geophys. Res. 102 2467-2474.

Shepherd G G, McLandress C and Solheim B H 1995 Tidal influence on $\mathrm{O}\left({ }^{1} \mathrm{~S}\right)$ airglow emission rate distributions at the geographic equator as observed by WINDII; Geophys. Res. Lett. 22 275-278.

Shepherd G G, Roble R G, Zhang S P, McLandress C and Wiens R H 1998 Tidal influences on midlatitude airglow: Comparison of satellite and ground-based observations with TIME-GCM predictions; J. Geophys. Res. 103 14,741-14,751.

Shepherd G G, Stegman J, Singer W and Roble R G 2004 Equinox transition in wind and airglow observations; J. Atmos. Sol. Terr. Phys. 66 481-491.

Siingh Devendraa, Singh R P, Singh A K, Kulkarni M N, Gautam A S and Singh Abhay K 2011 Solar activity, lightning and climate; Surv. Geophys. 32 659-703, doi: $10.1007 / \mathrm{s} 10712-011-9127-1$. 
Siingh D, Singh R P, Singh A K, Kumar S, Kulkarni M N and Singh Abhay K 2012 Discharge in stratosphere and mesosphere; Space Sci. Rev. 169 73-121.

Smith S M, Mendillo M, Baumgardner J and Clark R R 2000 Mesospheric gravity wave imaging at subauroral site: First results from Millstone Hill; J. Geophys. Res. 106 27,119-27,130.

Snively J B and Pasko V P 2008 Excitation of ducted gravity waves in the lower thermosphere by tropospheric sources; J. Geophys. Res. 113 A06303, doi: 10.1029/2007JA012693.

Takahashi H, Batista P P, Sahai Y and Clemesha B R 1985 Atmospheric wave propagation in the mesopause region observed by the $\mathrm{OH}(8,3)$ band, $\mathrm{NaD}, \mathrm{O}_{2} \mathrm{~A}(8645 \mathrm{~A})$ band and OI 5577 A nightglow emissions; Planet. Space Sci. 33 381-384.

Takahashi H, Gobbi D, Batista P P, Melo S M L, Teixeira N R and Buriti R A 1998 Dynamical influence on the equatorial airglow observed from the South American sector; Adv. Space Res. 21 817-825.

Tarasick D W and Hines C O 1990 The observable effects of gravity waves in airglow emissions; Planet. Space Sci. 38 1105-1119.

Tarasick D W and Shepherd G G 1992a Effects of gravity waves on complex airglow chemistries. $1 . \mathrm{O}_{2}\left(\mathrm{~b}^{1} \Sigma^{+} \mathrm{g}\right)$ emission; J. Geophys. Res. 97 3185-3193.

Tarasick D W and Shepherd G G 1992b Effects of gravity waves on complex airglow chemistries. 2. OH emission; J. Geophys. Res. 97 3195-3208.

Taori A and Taylor M 2010 Dominant winter-time mesospheric wave signatures over a low latitude station, Hawaii $\left(20.8^{\circ} \mathrm{N}\right)$ : An investigation; J. Earth Syst. Sci. 119 $259-264$.

Taori A, Guharay A and Taylor M J 2003 On the use of simultaneous measurements of $\mathrm{OH}$ and $\mathrm{O}_{2}$ emissions to investigate wave growth and dissipation; Ann. Geophys. 25 639-643.

Taori A, Taylor M J and Franke S 2005 Terdiurnal wave signatures in the upper mesospheric temperature and their association with the wind fields at low latitudes $\left(20^{\circ} \mathrm{N}\right)$; J. Geophys. Res. 110 D09S06, doi: 10.1029/ 2004JD004564.

Taori A, Guharay A and Taylor M J 2007 On the use of simultaneous measurements of $\mathrm{OH}$ and $\mathrm{O}_{2}$ emissions to investigate wave growth and dissipation; Ann. Geophys. 25 639-643, doi: 10.5194/angeo-25-639.

Taylor M J, Pendleton W R Jr, Gardner C S and States R J 1999 Comparison of terdiurnal tidal oscillations in mesospheric $\mathrm{OH}$ rotational temperature and $\mathrm{Na}$ lidar temperature measurements at mid-latitudes for fall/spring conditions; Earth Planets Space 51 877-885.

Thayaparan T 1997 The terdiurnal tide in the mesosphere and lower thermosphere over London, Canada $\left(43^{\circ} \mathrm{N}\right.$, 81ํ) ; Geophys. Res. Lett. 102 21,695-21,708.

Thayaparan T, Hocking W K and MacDougall J 1995 Observational evidence of tidal/gravity wave interactions using the UWO $2 \mathrm{MHz}$ radar; Geophys. Res. Lett. 22 $373-376$.

Tsuda T, Inoue T, Fritts D C, Vanzandt T E, Kato S, Sato T and Fukao S 1989 MST radar observations of a saturated gravity wave spectrum; J. Atmos. Sci. 46 2440-2447.

Vadas S L, Yue J, She C-Y, Stamus P A and Liu A Z 2009 A model study of the effects of winds on concentric rings of gravity waves from a convective plume near Fort Collins on 11 May 2004; J. Geophys. Res. 114 D06103, doi: 10.1029/2008JD010753.

Vincent G A, Nuno D and Hindmarsh M 1998 Numerical simulations of string networks in the Abelian-Higgs Model; Phys. Rev. Lett. 80 2277-2280.

Wiens R H and Weill G 1973 Diurnal, annual and solar cycle variations of hydroxyl and sodium nightglow intensities in the Europe-Africa sector; Planet. Space Sci. 21 1011-1027.

Won Y-I, Sivjee G G, Azeem S M I and Wu Q 2007 Tidal features in the wintertime mesospheric temperature and neutral winds recorded at Resolute Bay, Canada (74.681N, 94.901W); J. Atmos. Sol. Terr. Phys. 69 459-470.

Wu Q, Mitchell N J, Killeen T L, Solomon S C and Younger P T 2005 A high-latitude 8-hour wave in the mesosphere and lower thermosphere; J. Geophys. Res. 110 A09301, doi: 10.1029/2005JA011024.

Yudin V A, Geller M A, Khattatov B V, Ortland D A, Burrage M D, McLandress C and Shepherd G G 1998 TMTM simulations of tides: Comparison with UARS observations; Geophys. Res. Lett. 25 221-224.

Zhang S-P, Roble R G and Shepherd G G 2001 Tidal Influence on the oxygen and hydroxyl nightglows: WINDII observations and TIME-GCM simulations; J. Geophys. Res. 106 21,381-21,394.

Zhang S P, Goncharenko L P, Salah J E, Roble R G and Shepherd G G 2003 Climatology of neutral winds in the lower thermosphere over Millstone Hill $\left(42.6^{\circ} \mathrm{N}\right)$ observed from ground and from space; J. Geophys. Res. 108 1051-1062.

Zhao G, Liu L, Ning, B, Wan W and Xiong J 2005 The terdiurnal tide in the mesosphere and lower thermosphere over Wuhan $\left(30^{\circ} \mathrm{N}, 114^{\circ} \mathrm{E}\right) ;$ Earth Planets Space $\mathbf{5 7}$ 393-398. 